University of Wollongong

Research Online

Australian Institute for Innovative Materials -

Papers

Australian Institute for Innovative Materials

$1-1-2013$

Engineering a multimodal nerve conduit for repair of injured peripheral nerve

A F. Quigley

University of Wollongong, anitaq@uow.edu.au

$\mathrm{K} \mathrm{J}$. Bulluss

St Vincent's Hospital, Melbourne

I L. B Kyratzis

CSIRO

K Gilmore

University of Wollongong, kerryg@uow.edu.au

T Mysore

University of Wollongong, tharun@uow.edu.au

See next page for additional authors

Follow this and additional works at: https://ro.uow.edu.au/aiimpapers

Part of the Engineering Commons, and the Physical Sciences and Mathematics Commons

Research Online is the open access institutional repository for the University of Wollongong. For further information contact the UOW Library: research-pubs@uow.edu.au 


\title{
Engineering a multimodal nerve conduit for repair of injured peripheral nerve
}

\begin{abstract}
Injury to nerve tissue in the peripheral nervous system (PNS) results in long-term impairment of limb function, dysaesthesia and pain, often with associated psychological effects. Whilst minor injuries can be left to regenerate without intervention and short gaps up to $2 \mathrm{~cm}$ can be sutured, larger or more severe injuries commonly require autogenous nerve grafts harvested from elsewhere in the body (usually sensory nerves). Functional recovery is often suboptimal and associated with loss of sensation from the tissue innervated by the harvested nerve. The challenges that persist with nerve repair have resulted in development of nerve guides or conduits from non-neural biological tissues and various polymers to improve the prognosis for the repair of damaged nerves in the PNS. This study describes the design and fabrication of a multimodal controlled pore size nerve regeneration conduit using polylactic acid (PLA) and (PLA):poly(lactic-co-glycolic) acid (PLGA) fibers within a neurotrophin-enriched alginate hydrogel. The nerve repair conduit design consists of two types of PLGA fibers selected specifically for promotion of axonal outgrowth and Schwann cell growth (75:25 for axons; 85:15 for Schwann cells). These aligned fibers are contained within the lumen of a knitted PLA sheath coated with electrospun PLA nanofibers to control pore size. The PLGA guidance fibers within the nerve repair conduit lumen are supported within an alginate hydrogel impregnated with neurotrophic factors (NT-3 or BDNF with LIF, SMDF and MGF-1) to provide neuroprotection, stimulation of axonal growth and Schwann cell migration. The conduit was used to promote repair of transected sciatic nerve in rats over a period of 4 weeks. Over this period, it was observed that over-grooming and self-mutilation (autotomy) of the limb implanted with the conduit was significantly reduced in rats implanted with the full-configuration conduit compared to rats implanted with conduits containing only an alginate hydrogel. This indicates return of some feeling to the limb via the fully-configured conduit. Immunohistochemical analysis of the implanted conduits removed from the rats after the four-week implantation period confirmed the presence of myelinated axons within the conduit and distal to the site of implantation, further supporting that the conduit promoted nerve repair over this period of time. This study describes the design considerations and fabrication of a novel multicomponent, multimodal bio-engineered synthetic conduit for peripheral nerve repair.
\end{abstract}

\section{Keywords}

injured, peripheral, multimodal, engineering, nerve, conduit, repair

\section{Disciplines}

Engineering | Physical Sciences and Mathematics

\section{Publication Details}

Quigley, A. F., Bulluss, K. J., Kyratzis, I. L. B., Gilmore, K., Mysore, T., Schirmer, K. S. U., Kennedy, E. L., O'Shea, M., Truong, Y. B., Edwards, S. L., Peeters, G., Herwig, P., Razal, J. M., Campbell, T. E., Lowes, K. N., Higgins, M. J., Moulton, S. E., Murphy, M. A., Cook, M. J., Clarke, G. M., Wallace, G. G. \& Kapsa, R. M. I. (2013). Engineering a multimodal nerve conduit for repair of injured peripheral nerve. Journal of Neural Engineering, 10 (1), 1-17.

\section{Authors}

A F. Quigley, K J. Bulluss, I L. B Kyratzis, K Gilmore, T Mysore, K S U Schirmer, E L. Kennedy, M O'Shea, Y B. Truong, S L. Edwards, G Peeters, P Herwig, Joselito M. Razal, T E. Campbell, K N. Lowes, M J. Higgins, S E. Moulton, M A. Murphy, M J. Cook, G M. Clark, G G. Wallace, and R M. I Kapsa

This journal article is available at Research Online: https://ro.uow.edu.au/aiimpapers/602 


\section{Engineering a Multimodal Nerve Conduit for Repair of Injured Peripheral Nerve}

Quigley, A.F ${ }^{1,2,}$, Bulluss, K.J. ${ }^{2}$, Kyratzis I.L.B. ${ }^{3}$, Gilmore, K. ${ }^{1}$, Mysore. T. ${ }^{1,2}$, Schirmer, K.S.U. ${ }^{1,2,5}$, Kennedy, E.L. ${ }^{2}$, O’Shea, M. ${ }^{3}$ Truong, Y.B. ${ }^{3}$, Edwards, S.L. ${ }^{3}$, Peeters, G. ${ }^{3}$, Herwig, P. ${ }^{3}$, Razal, J. M. ${ }^{1}$, Campbell, T.E. ${ }^{1}$, Lowes, K.N. ${ }^{2}$, Higgins, M.J. ${ }^{1}$, Moulton, S.E. ${ }^{1}$, Murphy, M.A. ${ }^{2}$, Cook, M.J. ${ }^{2}$, Clark, G.M. ${ }^{1,4}$, Wallace, G.G. ${ }^{1 *}$, and Kapsa, R.M.I. ${ }^{1,2, *}$

1. ARC Centre for Electromaterials Science and Intelligent Polymer Research Institute, AIIM Facility, Innovation Campus, University of Wollongong, Squires Way, Fairy Meadow, NSW 2519, Australia;

2. Department of Clinical Neurosciences, St Vincent's Hospital, Melbourne and Department of Medicine, The University of Melbourne, Fitzroy, Victoria 3065, Australia;

3. CSIRO-Materials Science and Engineering, Clayton Victoria 3168, Australia

4. National Information and Communications Technology Australia,Victorian Research Laboratory, The University of Melbourne, Parkville, Victoria 3010, Australia.

5. Department of Bionics, University of Applied Sciences, Bremen Neustadtswall 30, D-28199, Bremen, Germany

\section{* Corresponding Authors:}

Robert M.I. Kapsa PhD,

Department of Clinical Neurosciences,

St Vincent's Hospital Melbourne,

41 Victoria Pde, Fitzroy,

Victoria, 3065,

Australia.

T: $\quad+61392883341$

F: $\quad+61392883350$

E: rkapsa@iinet.net.au
Gordon G Wallace PhD, ARC Centre of Excellence for Electromaterials Science Intelligent Polymer Research Institute AIIM Facility, Innovation Campus University of Wollongong, NSW 2522, Australia.

T: $\quad+61242213127$

F: $\quad+61242213114$

E: gwallace@uow.edu.au 


\begin{abstract}
Injury to nerve tissue in the Peripheral Nervous System (PNS) results in long-term impairment of limb function, dysaesthesia and pain, often with associated psychological effects. Whilst minor injuries can be left to regenerate without intervention and short gaps up to $2 \mathrm{~cm}$ can be sutured, larger or more severe injuries commonly require autogenous nerve grafts harvested from elsewhere in the body (usually sensory nerves). Functional recovery is often suboptimal and associated with loss of sensation from the tissue innervated by the harvested nerve. The challenges that persist with nerve repair have resulted in development of nerve guides or conduits from non-neural biological tissues and various polymers to improve the prognosis for the repair of damaged nerves in the PNS. This study describes the design and fabrication of a multimodal controlled pore size nerve regeneration conduit using polylactic acid (PLA) and (PLA):poly(lactic-co-glycolic) acid (PLGA) fibers within a neurotrophin-enriched alginate hydrogel. The Nerve Repair conduit design consists of two types of PLGA fibers selected specifically for promotion of axonal outgrowth and Schwann cell growth (75:25 for axons; 85:15 for Schwann cells). These aligned fibers are contained within the lumen of a knitted PLA sheath coated with electrospun PLA nanofibers to control pore size. The PLGA guidance fibers within the nerve repair conduit lumen are supported within an alginate hydrogel impregnated with neurotrophic factors (NT-3 or BDNF with LIF, SMDF and MGF-1) to provide neuroprotection, stimulation of axonal growth and Schwann cell migration. The conduit was used to promote repair of transected sciatic nerve in rats over a period of 4 weeks. Over this period, it was observed that over-grooming and self-mutilation (autotomy) of the limb implanted with the conduit was significantly reduced in rats implanted with the full-configuration conduit compared to rats implanted with conduits containing only an alginate hydrogel. This indicates return of some feeling to the limb via the fully-configured conduit. Immunohistochemical analysis of the implanted conduits removed from the rats after the four-week implantation period confirmed the presence of myelinated axons within the conduit and distal to the site of implantation, further supporting that the conduit promoted nerve repair over this period of time. This study describes the design considerations and fabrication of a novel multicomponent, multimodal bio-engineered synthetic conduit for peripheral nerve repair.
\end{abstract}




\section{Introduction}

Peripheral nerve (PN) damage causes loss of sensation and function in target organs ranging in severity from mild to severe incapacitation. Estimates from retrospective studies indicate that every year, more than one million people in the US suffer serious PN injuries arising from lower limb trauma alone [1], and that over 50,000 surgical procedures are performed on a yearly basis to correct injured $\mathrm{PN}[2]$. The incidence of neuropathies or nerve dysfunction due to other pathological processes such as diabetes [3;4] furthers the impact of PN injury as a major human health issue.

Varying degrees of nerve injury sub-classified at the fiber level, range from partial injuries, where there is temporary interruption to nerve transmission, complete interruption of transmission but with the nerve still intact, to the nerve being completely severed [5], and require different approaches to repair: Minor injuries, particularly to smaller monofascicular nerves in the peripheral nervous system (PNS), can regenerate without intervention whilst short gaps up to $2 \mathrm{~cm}$ can be repaired directly by suturing [6-8], Larger or more severe injuries however, are commonly treated by autogenous nerve grafts harvested from elsewhere in the body (usually sensory nerves). Such autografts restore some function, but are associated with loss of sensation in the tissue innervated by the harvested nerve[9].

Significant attention has thus been directed towards development of nerve guides or conduits based on allografts, xenografts and various bioresorbable or non-resorbable synthetic polymers in order to improve the prognosis for repair of damaged nerves in the PNS and avoid the loss of neural function caused by harvesting sensory nerve autografts [10-18]. Universally, the design of such nerve repair conduits aims to facilitate a neurotrophic environment that allows proper growth and reconnection of regenerating (damaged) axons with the distal end of the damaged nerve. This has resulted in the incorporation of a wide variety of materials, fabrication processes and trophic agents to produce the most effective nerve repair conduits: These include polymers such as collagen, poly-lactides, alginate, fibrin, keratin, chitin, Teflon (PTFE), spider silk and silicone [19;20], in addition to biological tissue-based materials including nerve, blood vessels and amniotic tubes [21-23]. Materials have been incorporated into nerve repair conduits as electrospun webs [13], fibers [24], sponges [25] and hydrogels [26]. Some positive results have been demonstrated with some of these materials in animals and in some case in humans, however efficacy remains variable [27;28]. In general, nerve repair conduits are still inferior in performance compared to the autogenous nerve graft [29]. It is nevertheless accepted that with further improvement, synthetic nerve guides provide an alternative for nerve repair [29]. In particular, use of synthetic conduits affords the major advantage that nerves once thought to be low priority for autograft (eg in the far periphery) due to their requirement of donor nerve from other regions, can be repaired without loss of sensation or function in "more important" regions of the body [30]. Likewise, conduits provide an alternative for the treatment of acquired nerve defects such as diabetic neuropathy [31].

Nevertheless, there are still considerable challenges and room for improvement for the use of synthetic conduits for nerve repair, particularly for longer nerve repair applications [32]. Improvement of nerve repair guides has mainly focused on the incorporation of trophic factors [33], such as Neurotrophin-3 (NT-3) [34], Brain-Derived Neurotrophic Factor (BDNF) [35] Leukemia Inhibitory Factor (LIF) [36-39], and Glial Growth Factor (GGF) [40]. In addition, a number of studies have incorporated extracellular matrix proteins, such as laminin and collagen resulting in improved nerve repair [25;41]. However, little attention has been paid to date as to the inherent proneural properties as opposed to the more generalized "biocompatibility" of the specific materials from which the conduits are made. As a consequence of this, the small number of commerciallyavailable conduits based on individual extracellular matrix proteins such as type I collagen (e.g. NeuraGen) have shown limited ability to support nerve regeneration and fail to confer the regenerative advantages achieved with nerve isografts in animals [42]. This sub-optimal capacity to support nerve regeneration, most likely due to the fact that current conduits do not accurately reflect 
the specific extracellular matrix of nerve, is highlighted by the fact that autogenous nerve grafts are still considered the "gold standard" of nerve repair and favoured by neurosurgeons, despite the commercial availability of "off the shelf" conduits [43].

Finally, advances in polymer fabrication technologies in recent times has enabled the fabrication of scaffolds with combined therapeutic modalities, as highlighted by co-incorporation of GGF and Schwann cells within a nerve repair conduit [44]. Multimodal delivery of bio-activities that individually target specific aspects of nerve repair using engineered conduits composed of multiple, likewise bio-selective materials to compartmentalize desired aspects of nerve repair and limit inhibitory activity, have great potential to improve surgical outcomes in nerve repair surgery.

This study communicates the design, experimental development and fabrication of a multimodal controlled pore size nerve regeneration conduit using polylactic acid (PLA) and poly(lactic-coglycolic) acid (PLGA) fibers within a neurotrophin-enriched alginate hydrogel for the promotion of nerve repair in an axotomized rat sciatic nerve. The Nerve Repair conduit design consists of two types of PLGA fibers selected specifically for their inherent promotion of Schwann cell growth primarily, and axonal outgrowth, with a secondary promotioin of axonal growth activity in preference to fibroblasts. These fibers are contained within the lumen of a knitted PLA sheath overlaid with electrospun PLA nanofibers to control pore size. The PLGA guidance fibers within the neural repair lumen are supported within an alginate hydrogel impregnated with neurotrophic factors (NT-3 with LIF, SMDF and MGF-1) for neuroprotection, stimulation of axonal growth and Schwann cell migration. This study describes a novel multimodal bio-engineered conduit for promotion of peripheral nerve repair. 


\section{Methods}

Polymer Formulations and Configurations:

\section{Polymers for Biocompatibility Assays:}

Eight formulations of Polylactic Acid (PLA) and Poly-DL-lactide/glycolide copolymers (PLGA) polymers were selected on their commercial availability and regulatory body (FDA) approval for use in humans. Polylactic acid 3051D (PLA) was obtained from Natureworks. PLGA copolymers were obtained from Purac Biomaterials. The grades of PLGA used were Purasorb PDLG 85:15 DLlactide/glycolide copolymer (inherent viscosity (i.v.) 0.84 dl/g), Purasorb PDLG 75:25 DLlactide/glycolide copolymer (i.v. $0.93 \mathrm{dl} / \mathrm{g}$ ) and Purasorb PDLG 50:50 DL-lactide/glycolide copolymer with i.v. values of 0.17, 0.37, 0.59, 1.05 dl/g. Lactel PLGA 50:50 ester terminated with i.v. 0.76-0.94 dL/g was obtained from from Durect Corporation, Pelham, AL, USA..

For evaluation of relative cytocompatibility for the various cell types, each polymer formulation was prepared as a $2 \%(\mathrm{w}: \mathrm{v})$ solution in chloroform and drop-cast in $100 \mu$ l volumes into wells of 96chamber microtitre plates. The chloroform was evaporated off in a fume hood overnight. The dried polymers were sterilized using $70 \%$ ethanol $(20 \mathrm{~min})$ which was then removed and allowed to dry off for 4 hrs under laminar flow prior to serial (5 times) washing and equilibration in cell growth media.

\section{Evaluation of Cytocompatibility and Cell Affinity for PLGA Formulations:}

In order to facilitate 'standardization' and more uniform comparability of cell response to the polymers, cell lines were used in preference to primary cultures. To evaluate each polymer's relative cytocompatibility and facilitation of cell growth, for each cell type, polymer formulations were drop cast (100 $\mu \mathrm{l}$ of $2 \%$ polymer in chloroform) in triplicate into 96 well plates. Cell-seeding densities of between 100 and $10^{4}$ cells per assay were used and measured by absorbance $\left(\mathrm{A}_{490}\right)$ of formazan product arising from the cytoplasmic reductase-mediated reduction of MTS reagent (3-[4,5dimethylthiazol-2-yl]-5-[3-carboxymethoxyphenyl]-2-[4-sulfophenyl]-2H-tetrazolium) and the electron coupling PMS (phenazine methosulfate) using the CellTiter 96 AQueous Non-Radioactive Cell Proliferation Assay (Promega). This avoided cell visibility issues caused by the porosity and opacity of the polymer formulations that arise using standard cell counting methods.

Cells were allowed to adhere to the various polymer formulations, over 72 hours $(6,24$, and 72 hours) to determine the polymer with the best adhesion and biocompatibility facilitation for each respective cell type. Differences in the empirical amounts of reductase activity (as measured by MTS) cell number in the PC12, RSC96 and Rat1-R12 cells (all purchased from the American Type Culture Collection; ATCC) were calibrated by comparison of known numbers of each respective cell type (100, 1000, 5000 and 10,000 cells): After correction for background absorbance, RSC96 cells (5000 cells) returned the highest $\mathrm{A}_{490},(0.671)$ followed by the Rat1-R12 (0.551) and then the PC12 cells (0.484). These data provided the calibration factors for subsequent MTS data to enable direct comparison of relative cell numbers via the MTS data: All subsequent absorbance data were expressed relative to RSC96 using calibration multipliers of 1.39 (PC12), 1.00 (RSC96) and 1.22 (Rat1-R12) that were applied to normalize the MTS readings for comparison of relative cell numbers between the different cell types. Early attachment (after 6 hrs), primary (24 hrs) and established (72 hrs) proliferative attachment were scored, calibrated (as above) and compared for each respective cell type on each polymer formulation evaluated. The data were subjected to statistical analysis using two-tailed Fisher's student $t$ statistic for unpaired samples with unequal variance to establish the statistical significance of differences observed between the test groups.

\section{PC12 (Neural), RSC96 (Schwann) and Rat1-R12 (Fibroblast) Cell Lines Culture:}

PC12, RSC96 and Rat1-R12 cells were grown in growth media containing DMEM with $4 \mathrm{mM}$ glutamine, $4.5 \mathrm{~g} / \mathrm{L}$ glucose, $1.5 \mathrm{~g} / \mathrm{L}$ sodium bicarbonate, $100 \mathrm{~g} / \mathrm{ml}$ streptomycin, $100 \mathrm{U} / \mathrm{ml}$ penicillin, $10 \%$ Fetal Calf Serum (FCS) or 5\% Horse Serum (for PC12s only) with media changes every $2^{\text {nd }}$ 
day. When sufficient cells were grown for experimentation, they were detached from tissue culture flasks using dissociation buffer containing $0.25 \%$ trypsin for 5 minutes at $37^{\circ} \mathrm{C}$ and transferred to 96 well microtitre plates with respective polymer formulations drop cast in the wells as outlined above.

After sterilization and equilibration of the polymer formulations, $1 \times 10^{4}$ PC12, RSC96 and Rat1-R12 cells were applied to each well in $100 \mu \mathrm{l}$ volume triplicates with growth media (as above). The cells were then incubated at $37^{\circ} \mathrm{C}$ (media changes every $2^{\text {nd }}$ day) in a humidified tissue culture (TC) incubator, for the appropriate period of time. The floating cells were removed, and polymers/cells washed twice in TC media before cell assay reagent (Promega AQeous MTS) was added to the cells, according to manufacturer specification. Cells were incubated with assay reagent for 4 hours in a TC incubator, before absorbance measurements (adjusted for background), were taken at 490nm. Values were adjusted for background and calibrated to normalize for metabolic differences and expressed as mean \pm s.e.m. Statistical analyses were carried out using two-tailed Fisher's student $t$ statistic for unpaired samples with unequal variance.

\section{Effects of Microfibers on Axonal Guidance and Schwann Cell Migration from DRG:}

Whole Dorsal Root Ganglia (DRG) explants were used to assess the effect of miscrostructure on axonal sprouting (neurite outgrowth) and guidance and Schwann cell migration on fibers formed from appropriately selected polymers. After hypothermia induced anaesthesia, 2-4 day old rat pups rat pups were euthanased and decapitated. The spinal cord was removed and discarded to expose the underside of the spinal column. Whole DRG were removed from the side of the spinal column using fine tweezers and placed into 1 x Hank’s Balanced Salt Solution (HBSS; Invitrogen).

The two biodegradable poly (DL-lactic-co-glycolic acid) co-polymer formulations (75:25 PLGA, 0.71 i.v., 110,000 Da and 85:15 PLGA, 0.84 i.v., 135,000 Da) determined to be optimal for axonal and Schwann cell growth respectively were wet-spun into fibers approximately $30 \mu \mathrm{m}$ in diameter as described below on gold mylar substrata. The entire microstructured assembly[45;46] was overlaid with a four-chambered polypropylene chamber slide assembly for analysis of axonal growth and Schwann cell migration guidance by the fibers as described elsewhere[45] to allow for rapid iterative cycles of evaluation and adjustment: Briefly, a solution of the selected polymer formulations in chloroform was injected into a $1.5 \mathrm{~cm}$-diameter tube filled with the coagulation solvent in a one metre long coagulation bath. The fibers were then collected around a collector spool containing prewashed (with ethanol) mylar or gold-coated mylar substrata. The spinning solution injection rate and the fiber collection speed were controlled at $1.8 \mathrm{ml} / \mathrm{hr}$ and $8.5 \mathrm{~m} / \mathrm{min}$, respectively, resulting in fibers of 30 um cross-sectional diameter. For this study, isopropanol was used as coagulation and wash solutions. After initial establishment of microstructure effects on a two-dimensional platform, the effect of micro-structured matrix on primary DRG explants was evaluated in a polypropylene tube (2 mm ID) containing PLGA fibers inserted into supporting alginate gel matrices. Fibers for the finalized conduit assembly were then formed using hot melt extrusion, which allowed the generation of larger lengths and quantities of fibers than did the wet-spinning process.

For DRG attachment, the substrata within the chambers were coated with $0.02 \mathrm{mg} / \mathrm{ml}$ laminin (Gibco; diluted in Hank's balanced salt solution; HBSS) by incubation at $37^{\circ} \mathrm{C}$ for $2 \mathrm{hr}$ after which they were rinsed twice with HBSS to remove excess laminin. DRG were placed into the chamber slides with appropriate microstructured substrata (as described in preceding text) containing DRG growth media (Neurobasal A containing 1 x B27, 4 mM L-glutamine, 1 x penicillin/streptomycin) and incubated at $37^{\circ} \mathrm{C}$ in humidified $5 \% \mathrm{CO}_{2}$. The DRG were allowed to attach onto the microstructured PLGA/Laminin [45;46] platforms for three days, with attachment confirmed by removal of media and mild rinsing with HBSS. DRG that remained attached after the rinses were then grown for a 30-day period with media changes every two days to evaluate the effect of the microfibers on axonal outgrowth and Schwann cell migration from the DRG explant body. Axons 
were visualized by immunohistochemical staining for $\beta$ III Tubulin, Schwann cells with S100 $\beta$ and cell nuclei (Schwann cells and fibroblasts) with DAPI as described below. Cells staining positive for DAPI, but negative for either $\beta$ III Tubulin or S100 $\beta$ were assigned to be non-neural Fibroblast cells.

\section{Immunohistochemistry:}

Polymer Biocompatibility/Optimization: Cell adherence to each polymer sample was validated by staining and visualization of cell nuclei. At each time point the culture media were removed and the polymer samples washed twice by slow immersion in $0.5 \mathrm{ml}$ PBS. Adherent cells (cells remaining) were fixed in $4 \%$ paraformaldehyde for $15 \mathrm{~min}$ at room temperature. Cells were then stained with DAPI (Sigma) for $10 \mathrm{~min}$ at room temperature to allow visualization. Photomicrographs of 5 representative fields of view on each polymer disc were taken under UV fluorescence using an Olympus IX70 inverted microscope and liquid-cooled CCD digital camera (SPOT Diagnostics RTSlider).

Relative Axonal, Schwann Cell and Fibroblast Growth: After removal of culture media, the growth platform was washed twice by slow immersion in $0.5 \mathrm{ml}$ PBS. The cells were fixed in $4 \%$ paraformaldehyde for $15 \mathrm{~min}$ at room temperature. After fixation, the scaffolds were incubated in $10 \%$ donkey serum (Chemicon) for 1 hour at room temperature. The scaffolds were then incubated with both rabbit anti- $\beta$ III Tubulin (1:1,000 dilution, Covance) and mouse anti-S100 $\beta$ (1:2,000 dilution, Sigma) at $37^{\circ} \mathrm{C}$ for 1 hour to visualize neuronal growth and Schwann cell migration respectively from the DRG. After incubation, the primary antibodies were removed and scaffolds washed in $1 \mathrm{x}$ PBS, before incubation at $37^{\circ} \mathrm{C}$ for 1 hour with alexafluor donkey anti-rabbit and donkey anti-mouse secondary antibodies (Molecular Probes; both at 1:2,000 dilution) in 10\% donkey serum. The secondary antibodies were then removed, scaffolds washed once in PBS for 5 minutes and stained with DAPI (200 ng/ml) for 15 minutes at room temperature. The scaffolds were then placed in a 6 well dish for visualization and photomicrography.

\section{Conduit Development and Fabrication:}

In vitro experiments indicated that the 75:25 and 85:15 PLGA formulations were optimal for use as fibers within the proposed conduit lumen. In addition, the PLA polymer was selected as the material for the outer wall of the conduit due to its comparatively robust nature compared to the other polymers evaluated. The design for the nerve conduit sheath incorporated a knitted tube, providing appropriate mechanical properties to the conduit, with an electrospun membrane dictating the construct's permeability to trophic environmental factors and external cells. Guidance fibers were set in a trophic hydrogel within the lumen of the conduit. Stage-wise fabrication of the conduit involved production of the knitted tube with electrospun outer membrane, (pore size $<2 \mu \mathrm{m}$ ). The conduit was then filled with 75:25 and 85:15 melt-extruded PLGA fibers, and an alginate hydrogel containing growth factors for the promotion of axonal sprouting and Schwann cell development throughout the conduit.

\section{Melt Extrusion of Fibers:}

Previous studies [47] found improved neurite outgrowth and Schwann cell migration along $30 \mu \mathrm{m}$ diameter polypropylene fibres, compared to larger fibres $(100-500 \mu \mathrm{m})$. Fibers for knitted sheath fabrication and for incorporation as axonal guidance fibers used PLGA formulations (Purac). PLA, PLGA 75:25 and 85:15 were dried to <20ppm water content using a dehumidifyer at $80^{\circ} \mathrm{C}$ overnight. The polymers were then cryo-ground to a powder to enable accurate feeding into the extruder. Polymers were fed at a rate between 0.3 to $1 \mathrm{~g} / \mathrm{min}$ into a twin screw extruder (Prism Eurolab 16) fitted with a gear pump (Barrell) and heated from $175^{\circ} \mathrm{C}$ to $195^{\circ} \mathrm{C}$ at the rod die $(0.3 \mathrm{~mm})$. The extrudate fibres were air-cooled and the fiber diameter and morphology was controlled via a godet system of heated and unheated rollers (Retech) incorporated into the extrusion line. Fiber diameters were determined by optical and scanning electron microscopy. These extruded fibers, of diameter 90 
to 100um were used for knitting the outer sheath and extruded fibers with 30-40 um diameter were used as nerve guidance fibers within the sheath lumen.

\section{Knitting and Electrospin-Coating of the Conduit Sheath:}

The conduit sheaths were knitted as a circular tube, with an internal diameter of $2 \mathrm{~mm}$, from extruded PLA monofilament yarn of 90 to $100 \mu \mathrm{m}$ diameter, using a Harry Lucas circular knitting machine 1/12 inch diameter over five needles (approx. fifteen needles per inch). PLA nanofibers were electrospun onto the knitted sheath to generate a "membrane" of controlled pore size, with pores no greater than, $2 \mu \mathrm{m}$ in diameter. Pores of this size have been found by others to be beneficial to nerve regeneration in vivo [48] and are of sufficiently small size to exclude entry of cells through the sheath wall. PLA nanofibers were deposited onto the knitted sheath by mounting the sheath through its lumen onto a grounded stainless steel collector rod. The rod was tilted to ensure a random deposition of the electrospun layer, and connected to a variable-speed motor. PLA (15\% w/w) in chloroform was electrospun onto the sheath using $15 \mathrm{~cm}$ distance to target and an applied electric field of $20 \mathrm{kV}$ at a solution feed rate of $0.2 \mathrm{ml} / \mathrm{hr}$. This resulted in an interconnected membrane of PLA nanofibers, with a large surface area per unit mass ratio.

\section{Multimodal Alginate Neuromatrix:}

Cross-linked alginate has been shown to be a suitable matrix for the promotion of nerve repair in early studies [36;37] and was selected on this basis as the primary matrix material for the nueromatrix component of the conduit. In the first instance, whole DRG explants were used to test the capacity of alginate to support neurite outgrowth and Schwann cell migration from the main body of the DRG: Several formulations of alginate (0.5-1.5\% alginate) were cross linked with $\mathrm{CaCO}_{3}$ to establish optimal gel densities for the promotion of nerve growth (data not shown). Filter sterilized alginate was cross linked either in petri dishes or in sterile glass vials for DRG explant culture growth analysis.

The specific modalities and molecular pathway utilization of several neurotrophins and trophic biofactors provide good rationale for the design of an augmentative synergistic multi-modal neuroregenerative function that elicits neurogenic or otherwise neurotrophic effects by enlisting several independent neurotrophic pathways: Neurotrophin-3 (NT-3) [34], Brain-derived Neurotrophic factor (BDNF) [12;35], a 24 residue peptide of the Insulin-derived Growth Factor 1E (IGF-1Eb) splice variant (Mechano Growth Factor-1 MGF-1) [49-51], Neuregulin 1 isoform, Sensory and Motor Neuron-Derived Factor (SMDF) [52;53] and Leukaemia Inhibitory Factor (LIF) [36;37] were specifically selected as components within the conduit hydrogel on this basis:- NT-3 promotes neurogenesis via TrkC with secondary activation through TrkA and TrkB pathways, whilst BDNF works through TrkB receptor pathways. Both of these neurotrophins are factors implicated in sensory and motor neuromuscular junction formation at muscle spindles and otherwise as potent neuroprotective agents compared to other neurotrophins.[54;55] LIF promotes survival of injured motor neurons through activation of the gp130 receptor pathway, similar to other neuropoietic cytokines such as ciliary neurotrophic factor (CNTF) but with more defined neurotrophic effects.[55;56] SMDF is highly expressed in motor and sensory neurons[57] and indirectly promotes neurotrophic effects through stimulation of Schwann cell growth via epidermal growth factor receptor (EGFR) pathways.[52;53] MGF-1 has been shown to promote neurotrophic effects, particularly on motor neurons via an as-yet uncharacterized receptor pathway distinct from that of IGF-1.[49;58;59]

The multimodal neuromatrix' specific biofactor constitution was developed independently by inclusion of each respective sub-component in amounts ranging between 1 and $200 \mathrm{ng} / \mathrm{ml}$ into dissociated DRG sensory neuron cultures in vitro to evaluate the optimal growth factor configuration for ultimate incorporation into the conduit: In the first instance, working concentrations of each of 
these bio-factors were optimized individually using dissociated DRG pseudo-bipolar sensory neurons and the extent of axonal outgrowth measured and analysed microscopically using NeuronJ software[60] in a minimum of 500 independent neurons distributed throughout biological triplicate (neurons derived from 3 separate animals) experiments to determine their most effective concentrations. These data were then pooled and statistically analysed using the student $t$ statistic (two-tailed, equal variance, unpaired samples) to determine the multimodal mixture that would result in the best synergistic neuro-regenerative response (Table 1).

\section{Development and Testing of Inner Neuromatrix Conduit Core ex vivo:}

The two most effective potential multimodal mixtures (NT-3 and BDNF configurations with MGF-1, SMDF and LIF) were then used to grow whole DRG ex vivo in polyethylene (PE) tubing with a 2 mm inner diameter (Accurel, Akzo Chemicals Limited) designed to simulate the conduit environment, containing 0.75\% alginate with 75:25 and 85:15 PLGA fibers and each respective multimodal neurotrophic mixture in order to confirm the in vitro dissociated DRG neuron results. Alginate containing one of the two "optimal" combinations of the proposed biofactors was crosslinked inside the lumen of the polyethylene (PE) tubing with an internal diameter of $2 \mathrm{~mm}$ (diameter of the rat sciatic nerve). PLGA fibers were included in some of these PE tubes, whilst other tubes contained hydrogel alone to evaluate the effect of the fibers on DRG neuronal growth compared to growth in the absence of fibers. DRG of similar size between individual applications were placed inside the polyethylene tubing, partially withdrawn from the tube and trimmed after the neuromatrix formulations had set, to accommodate the placement of the DRG. The tubing, containing alginate neuromatrix formulations, combinations of 85:15 and 75:25 PLGA fibers and DRG were placed in 24-well plates and covered with DRG growth media containing Neurobasal A (Invitrogen), 1 x B27 supplement (Invitrogen), 2 mM L-Glutamine (Invitrogen) and 100 units/ml Penicillin and 100 $\mu \mathrm{g} / \mathrm{ml}$ /Streptomycin (Invitrogen). The DRG were then allowed to grow as described above for 2-3 weeks (with media changes every two days) at which point they were harvested and analysed for neuronal outgrowth and Schwann cell migration. DRG growth dynamics were assessed using DAPI staining to visualize Schwann cell growth as an overall measurement of DRG nerve growth incursion into the matrix along the fibers which was measured (within the limitations imposed by the opacity of the PE capillaries) under microscopy using a graticule. In conjunction with the dissociated DRG neuron experiments, this provided a confirmatory basis by which the optimal neuromatrix composition was determined for incorporation into the conduit design.

In addition to biofactor and alginate composition of the hydrogel, the number of fibers to be placed within the lumen was investigated by this method. Others have previously reported that packing densities (using approx. $50 \mu \mathrm{m}$ PLA fibers within a $1.5 \mathrm{~mm}$ internal diameter silicone cuff) of between 3.5 and 7.5\% internal surface area packing densities yielded the most effective repair, but that the higher density resulted in more uniform placement of the fibers within the cuff lumen [61]. In our study, PE tubes were loaded with 150, 300, and 600 fibers at a 1:1 (75:25):(85:15) PLGA copolymer ratio. These numbers represented $4.1 \%, 8.3 \%$ and $17 \%$ of the proposed conduit's luminal cross-sectional area respectively. These tubes were then loaded with DRG, which were allowed to grow as described above and evaluated for outgrowth onto the fibers within the PE tube.

\section{Assembly of the Nerve Repair Conduit for Implantation:}

The extruded fibers and knitted/electrospun conduit sheath were fabricated separately to facilitate sterilization for implantation. Immediately prior to implantation, 75:25 and 85:15 PLGA fibers ( $n=150$ of each type) were threaded into the lumen of the conduit sheath and a solution of alginate containing the bio-factor components $(50 \mathrm{ng} / \mathrm{ml}$ each) was prepared. Crosslinking of the alginate/biofactor solution with $\mathrm{CaCO}_{3}$, was initiated in situ by Gluconolactone after which it was injected into the assembled conduit and allowed to set overnight at $4^{\circ} \mathrm{C}$ for implantation the next day. 
Control conduits, consisting of the knitted/electrospun sheath with the alginate hydrogel and no fibers or biofactors were also assembled for implantation.

\section{Surgical Implantation of Nerve Repair Conduit:}

Eight male Sprague Dawley Rats (8 weeks of age) were anesthetized by inhalation of a mixture of isoflurane $1 \% \mathrm{v} / \mathrm{v}$ and oxygen $(2 \mathrm{~L} / \mathrm{min})$. Rats were placed on warming pads to maintain body temperature and anaesthesia was maintained throughout the whole procedure by nose cone inhalation. The fur was shaved, cleaned with ethanol (swab), prepped with 10\% iodine cutaneous disinfectant (Povidone, Pfizer) and a dorsal gluteal incision made through the skin. The sciatic nerve was exposed within the hamstring component of the thigh and a $12 \mathrm{~mm}$ section of nerve was removed $10 \mathrm{~mm}$ distal to the inferior border of the piriformis muscle. Care was taken to preserve branches to the extensor musculature of the thigh. A conduit, of the same size as the removed nerve section was sewn into the nerve to bridge the gap. Four rats were implanted with empty conduits, whilst the other four were implanted with conduits containing fibers and NT-3 based hydrogel neuromatrix as specified in the preceding text. Three sutures were sewn through the epineurium of the distal and proximal stumps to hold the conduit in place by the conduit sheath wall using 10-O nylon. The wound was closed in a layered manner with 4-O Viacryl to the fascia lata and subcutaneous tissue while metal (Michel) clips were used to close the skin. The animals were allowed to recover before being placed back in their cages and given Bactrim $(0.2 \mathrm{mg} / \mathrm{ml}, 90 \mu \mathrm{g} / \mathrm{g})$ for 24 hours post procedure. All surgical procedures were carried out using sterile techniques and were approved by an institutional ethics committee (SVHM AEC approval \#80/07).

\section{Analysis of Axotomized Rat Sciatic Nerve Regeneration}

Over the four-week period of implantation, the rats were monitored for signs of discomfort, including autotomy of digits from the nerve transection. Autotomy of the axotomized limb occurs as a result of the rats feeling pain from the axotomy and an inability for the rat to feel pain in attempting to "groom" the perceived site of the pain [62]. Correct nerve resuturation has been shown to significantly decrease autotomy in rats [63] and has been previously used by other investigators as an assessment of nerve restoration, particularly where conduits have been used as a means of accelerating nerve regeneration[64]. The animals were scored for extent of autotomy using an autotomy scale from $0-4$ where $0=$ no evidence of autotomy, $1=1$ toe affected, $2=2$ toes affected, $3=3$ toes affected and $4=4$ toes affected [62]. The results were statistically evaluated using nonparametric Chi square statistic with a null hypothesis that the number of autotomized digits would not differ between rats implanted with empty (non-functional) conduits compared to rats implanted with fully functional conduits if the fully functional conduits were not effective.

At the end of the four-week implantation period, the animals were euthanased by a lethal dose of sodium pentobarbitone at a concentration of $60 \mathrm{mg} / \mathrm{ml}$ given at a dose rate of $(200 \mathrm{mg} / \mathrm{kg})$, administered by intraperitoneal injection. At this point, the extent of autotomy was scored by counting the number of digits mutilated in each group implanted with neuromatrix-containing conduits and compared to rats with conduits containing empty sheaths (no hydrogel and no fibers). The animals were then dissected to remove the conduit and approximately $3-4 \mathrm{~mm}$ of the attached distal and proximal nerve. The nerve and conduit was immediately placed in $10 \%$ formal saline and left for 24 hours, before embedding in paraffin. Paraffin sections were cut at 8-10 $\mu \mathrm{m}$, and dewaxed through a standard alcohol series. The nerve sections were immunolabelled with rabbit anti-Beta-III Tubulin (Covance, Tuj-1 clone, 1:1000 dilution) and alexafluor donkey anti-rabbit (Molecular Probes, 1:2000 dilution) antibodies before counterstaining with $200 \mathrm{ng} / \mathrm{ml}$ DAPI in PBS (Sigma). Sections were cover-slipped in fluorescent mounting media (DAKO) and viewed under fluorescence using an Olympus IX70 inverted microscope. Digital images were captured using a SPOT-RT Slider camera and SPOT software (Diagnostic Instruments). 


\section{Results:}

\section{Bio-Affinity of Polymers for Neuronal and Schwann Cell Types:}

Cell numbers were evaluated on each polymer formulation using the MTS assay with data that were calibrated to account for inter-cell type differences in inherent cytoplasmic reductase activities between the three cell types used. To enable direct comparisons, the "raw" data were expressed relative to the reductase activity detected in $5 \times 10^{3}$ RSC96 cells, which yielded $139 \%$ and $122 \%$ of the reductase activities of $5 \times 10^{3}$ PC12 and Rat1-R12 cells respectively. The respective capacities of the PLGA co-polymer formulations to support neuroregeneration were evaluated using an elimination process devised to establish their potential to promote attachment and growth of the functional cells (neurons and Schwann cells) of the damaged nerve over the inhibitory cells (fibroblasts) at the site of nerve injury: As such, the polymers selected for inclusion into the proposed nerve repair conduit would ideally support attachment and growth of neurons and supportative neuroglia (Schwann cells) in preference to the growth of inhibitory fibroblasts. Selection of the best polymer formulations for inclusion into the conduit lumen was achieved by comparison of relative attachment of neuronal (PC12), Schwann (RSC96) and fibroblast (1-R12) rat cell lines firstly at the early attachment stage (6 hrs), a later attachment/early proliferative stage during the first full proliferation cycle of the cells (24 hrs), and then after two further proliferative cell cycle periods (72 hrs).

"Immediate" Attachment Affinity of PC12, RSC96 and Rat1-R12 cell lines for Polymers: First 6 hrs: Analysis of cell attachment after the first 6 hrs' exposure to each polymer (Fig 1B) indicated that the 75:25 polymer formulation supported attachment of PC12, RSC96 and Rat1-R12 essentially to an equal extent, but slightly favouring fibroblasts. During this time however, statistically significant differences in favour of neuronal $(\mathrm{p}<0.01)$ and Schwann $(\mathrm{p}<0.005)$ cell lines' attachment over fibroblasts were observed on the 85:15 PLGA formulations. Schwann cell attachment to the 85:15 formulation was demonstrably higher than the neuronal cell line $(\mathrm{p}<0.02$, Fig $1 B)$.

\section{"Initial” Attachment Affinity of PC12, RSC96 and Rat1-R12 cell lines for Polymers: First 24 hrs:}

The cell attachment dynamics observed after the first 6 hrs differed after the first 24 hrs, a period reflective of an early proliferative timepoint (ie $<1$ full cell division cycle). At this stage, Schwann cell numbers were significantly greater than either neuronal or fibroblast cells on both 75:25 $(\mathrm{p}<0.03$; $\mathrm{p}<0.01$ respectively) and 85:15 ( $<<0.02$ and $\mathrm{p}<0.005$ respectively) formulations (Fig $1 \mathrm{C}$ ). Whilst fibroblast numbers on the 75:25 formulation were greater than those of the neuronal cell line $(p<0.0001)$, there were greater numbers of neuronal cells than fibroblasts on the 85:15 formulation $(\mathrm{p}<0.01)$.

"Sustained" Affinity of PC12, RSC96 and Rat1-R12 cell lines for Polymers: First 72 hrs:

After 72 hrs' growth, both of the polymer formulations supported significantly greater neuronal and Schwann cell line growth to a greater extent than the fibroblasts (Fig 1D). Importantly, there was no expansion of fibroblasts on either of these polymer formulations after $72 \mathrm{hrs}$ compared to the 24hr timepoint, indicating that protracted fibroblast proliferation would be contained to minimum over time on these polymers. In contrast, there were appropriate increases in PC12 and RSC96 numbers on both polymers, indicating that these cells' growth is preferentially supported to that of fibroblasts as time progresses. Whilst differences in PC12 and RSC96 cell numbers did not reach statistical significance on the 75:25 formulation, both yielded significantly greater numbers compared to the fibroblasts $(\mathrm{p}<0.005$ and $\mathrm{p}<0.009$ respectively). Both Schwann and neuronal cells' numbers were significantly greater after 72 hrs' growth on the 85:15 formulation $(\mathrm{p}<0.01$ and $\mathrm{p}<0.0003$ respectively) than the fibroblasts (Fig 1D). However, a much greater affinity of this formulation to the RSC96 cell line than the PC12 cells was demonstrated by the significantly greater numbers of these cells than the PC12s $(\mathrm{p}<0.01)$. As suggested by the proposed schematic at the bottom of the panels in Figs 1A-D, these results collectively provide a rationale for preferential establishment of neuronal and neuroglial with some (but limited) fibroblast cell growth if these polymer formulations 
were localized to the nerve injury environment. This rationale provided the initial basis for the choice of fiber materials for the internal lumen of the nerve repair conduit.

\section{Multi-Modal Synergistic Neurotrophic Fiber/Neurogel Conduit Core Development (in vitro):}

The competitive environment potentially encountered by the three cell types in vivo was investigated in vitro using Dorsal Root Ganglion (DRG) explants. These explants contain a multicellular in vitro environment that includes sensory neurons, Schwann cells and fibroblasts and thus represent (at least to some extent) the competitive cellular environment existent at the site of nerve injury. Several insights into the potential behaviour of regenerating nerve were thus obtained using this system: Firstly, DRG neurite outgrowth and Schwann cell migration on a substrate devoid of fibers occurred in a radial manner with no overt directional control (Fig 2A). In contrast, using a platform with PLGA fibers (75:25 or 85:15) attached on a supporting background coated with laminin [45;46], both axonal outgrowth and Schwann cell migration were observed to follow a linear path dictated by the direction of the fibers (Fig 2B). Importantly, the Schwann cells were seen to migrate and grow along the fibers and direct the extending axonal projections, giving rise to the possibility that in vivo, Schwann cell-mediated trophic signalling and myelination of axons would be facilitated on the fibers. This result differs somewhat to the work of others, who showed that whilst neurite growth and Schwann cell migration from DRG essentially coincided on laminin-coated $30 \mu \mathrm{m}$ polypropylene filaments, a slightly greater neurite outgrowth than Schwann cell migration was evident [47]. However, those studies involved DRG growth within a poly(acrylonitrile-co-vinyl chloride) (PANPVC) tube and as such involved different polymers and are only indirectly comparable with those presented here. Thirdly, evaluation of this growth response using immuno-histochemistry for S100 $\beta$ (Schwann cell antibody) and nuclear DAPI staining to differentiate Schwann cells (S100 $\beta$-positive, DAPI-positive) from fibroblasts (S100 $\beta$-negative, DAPI-positive) also confirmed that fibroblast activity was a minimal component of the DRG growth behaviour on these fibers, which also guided neuronal growth in a linear manner. This was evident in the presence of fibers (Fig 2B), whilst absence of fibers on the growth substrate promoted discrete regions of aggregated fibroblast deposition that appeared to exclude axonal tracking ("Fb" in Fig 2A).

Multimodal Neuromatrix: BDNF and NT3 are well-characterized neurotrophins that promote neuronal outgrowth in vitro and promote a neuroprotective environment in damaged nerve in vivo. The authors have previously used polypyrrole (pPy) for controlled delivery of NT3 and BDNF to promote the growth of auditory neurons in vitro [65-67]. In this (current) study, the possibility of promoting a multimodal synergistic nerve growth response was explored by application of either NT3 or BDNF, in conjunction with factors known to promote neuroprotective (LIF), Schwann cell trophic (SMDF) and otherwise neurotrophic response (MGF-1) to facilitate effective peripheral nerve repair and reinnervation of target muscle. The individual effects of each respective bio-factor on neuronal outgrowth were evaluated by exposure of primary pseudo-bipolar neurons dissociated from DRG and grown in vitro over 48 hours in the presence of each bio factor, after which the extent of neurite extension on individual neurons (100 to 120 neurons per factor) was measured using image analysis (ImageJ/NeuronJ sub-program)[60]. In the first instance, MGF-1 had no effect on its own on axonogenesis. The results of dissociated DRG neurite growth under the influence of Laminin and on Laminin in the presence of BDNF, NT3, LIF and SMDF respectively, are presented in Table 1. These results formed the basis for selection of the specific neuromatrix configuration: In the first instance, NT3 promoted 50\% more neurite outgrowth than did BDNF $(p<0.001 ; t)$. In addition, LIF displayed some neurotrophic activity alone compared to cells grown on Laminin, whilst SMDF did not. These results showed that the multimodal principle proposed in this study, utilizing different molecular pathways to promote a synergistic effect on nerve regrowth (Fig 1) would best involve the stimulation of Trk receptor pathways using NT3 and gp130 pathways via LIF because there appeared to be a robust difference in the extent to which these two factors exerted their neurotrophic effect $\left(p<1 \times 10^{-6}\right)$. On the other hand the extents of BDNF and LIF neurotrophic effects respectively, which 
likewise acted via Trk and gp130 receptor pathway activation, did not differ statistically from each other ( $p<0.06$, not significant; NS, Table 1$)$. The final aspect that determined NT3 as the "preferred" neurotrophin component of the multimodal neuromatrix involved consideration of the neuromatrix' requirement for SMDF-mediated promotion of Schwann cell migration and proliferation to provide a more native neurotrophic effect: This requirement is facilitated by the reported enhancement of Schwann cell migration by NT3, compared to BDNF, which inhibits Schwann cell migration [68].

The in vitro neuromatrix variants containing either NT3 or BDNF were validated using a model conduit core prior to fabrication and implantation of the conduit into axotomized rats. This modelling utilized a $2 \mathrm{~mm}$ diameter polyethylene tube into which fibers and alginate hydrogel were set in the lumen (Figs $2 \mathrm{C}$ to $2 \mathrm{E}$ ). In the first instance, this confirmed that growth through the $0.75 \%$ alginate matrix occurred to a greater extent and in a linear guided manner in the presence of fibers, compared to alginate devoid of fibers where the DRG did not grow into the gel at all. It was found also that of tubes containing 150, 300, and 600 fibers at a 1:1 ratio of (75:25):(85:15) PLGA fiber ratio, 300 fibers optimally allowed ingress of Schwann cells into the hydrogel. Greater numbers of fibers (600) were difficult to load into the lumen and when assembled did not permit ingress of DRG axons and Schwann cells, whilst 150 fibers were loosely and non-uniformly placed within the lumen. The 300 fibers identified here as optimal in vitro occupied a $8.3 \%$ of the cross-sectional area of the lumen, consistent with others' finding that a cross-sectional area of $7.5 \%$ provided a workable compromise between in vivo support of effective nerve repair and mechanical integrity and structural uniformity of the lumen environment [61]. Whilst the presence of fibers guided axonal outgrowth, it was evident that in the absence of stimulation from growth factors, Schwann cell migration and any consequential possible axonal outgrowth from the DRG were limited (Fig 2A). In addition, these experiments provided rationale for the inclusion of MGF-1, whose inclusion as a neuromatrix component with the other factors significantly improved incursion of DRG growth into the hydrogel/fiber core than with neurotrophic combinations in which MGF-1 was omitted (Data not shown). This result was interesting, given that MGF-1 alone did not promote any overt improvement in nerve growth into the hydrogel/fiber matrix over that observed in the alginate/fiber matrix in absence of growth factors. This result suggests that there is some augmentation of neurotrophic effects of the other biofactors by the MGF-1. Furthermore, this may be related to pathways that mediate in the selective neuroprotective activity of MGF-1 on motor neurons rather than sensory neurons as found in DRG.[69] This latter point is important in that the inclusion of MGF-1 potentially provides a multimodal synergistic neuroprotective effect that targets the various sensory and motor neurons, in addition to Schwann cells found in peripheral nerve and as such, gives rise to an environment capable of providing tightly controlled neuroregeneration.

\section{Application of the Nerve Repair Conduit to Sciatic Nerve Axotomy:}

The essential process of fabrication and implantation of the nerve repair conduits until harvest is outlined in Figure 3: After extrusion of 75:25 and 85:15 PLGA fibers (Fig 3A) and production of the electrospun conduit sheath (Figs 3B and 3C), the "neuro-optimized" nerve repair conduit with controlled pore sizes of around $2 \mu \mathrm{m}$ (Fig 3D) was assembled under sterile conditions with 150 of each type of fiber (300 fibers in total), an hydrogel containing NT3, SMDF, MGF-1 and LIF (50 $\mathrm{ng} / \mathrm{ml}$ of each) and allowed to cross-link overnight at $4^{\circ} \mathrm{C}$ (Figs $3 \mathrm{E}$ and $3 \mathrm{~F}$ ).

The assembled nerve repair conduits (Figs 3A to 3F) either with or without the complete NT-3-based hydrogel, and 150 75:25 and 150 85:15 PLGA fibers were implanted into rats $(n=4)$ with axotomized sciatic nerves (Fig 3G) for a period of 4 weeks after which the extent of autotomy (self-mutilation of paws in the implanted limb) was scored, the animals given lethal doses of sodium pentobarbitone and the nerve grafts removed (Fig 4A) for analysis. After removal, the sciatic nerve portions were analysed for axonal outgrowth and Schwann and fibroblast cell migration into the conduit lumen. 
Initial examination of the conduits in each rat after the 4-week implantation period revealed patent sciatic nerve proximal and distal to the nerve repair conduit implantation site only in animals with conduits containing the fully configured neuromatrix. An example of this is shown in Figure 4A. In addition, immunohistochemical analysis longitudinally along the length of the nerve injury and implanted nerve repair conduit indicated that neuronal outgrowth had extended to (Fig 4C), within (Fig 4D) and into the sciatic nerve distal to the axotomy (Fig 4E). Further immunohistochemical examination of the nerve tissue within the conduit revealed that in addition to axonal outgrowth into and beyond the conduit, at least some of the repaired axons were myelinated (Fig 5B). These results were consistent within all of the conduits harvested from the implanted rats.

During the 4 week implantation period, the rats were monitored daily for behavioural signs of distress and the effects of the sciatic nerve axotomy. At the point of euthanasia and removal of the conduit, autotomy of the axotomized limb was scored and compared in rats implanted with empty "sham" conduits and in rats implanted with fully assembled conduits. Significantly reduced levels of autotomy were observed in rats implanted with conduits containing the fully-configured neuromatrix compared to rats implanted with conduits containing just the conduit sheath (Fig $5 \mathrm{C}, \mathrm{p}<0.04 ; \chi^{2}$ ), This result is consistent with others' finding that silicone cuffs containing PLA fibers promoted significantly more effective nerve lesion repair in vivo than did silicone cuffs without fibers [61]. 


\section{Discussion:}

This study investigated the material, structural and biochemical design of a conduit for the repair of damaged peripheral nerve using the axotomized sciatic nerve rat model. The study specifically evaluated commercially available, regulatory body (FDA)-approved materials for use in the conduit on the basis of their potential to select for the growth of key functional cell types (neurons and Schwann cells) likely to be encountered at the site of nerve injury in preference to the growth of fibroblasts. This selective principle gives rise to the possibility that inhibitory (fibroblast) cellular activity may be limited to satisfactory levels simply by virtue of inherent bionic properties of the materials from which the conduit was fabricated. This study aimed to build this concept into a conduit that would facilitate effective peripheral nerve repair through compartmentalizing the key functional components of the neuro-regenerative process by providing them with "preferred" substrata within the conduit lumen. In the first instance, it was determined that PLGA with 75:25 and 85:15 co-polymer ratios were the optimal formulations for fabrication of conduit fibers that facilitated Schwann cell attachment, migration and growth as a conditioning bio-activity for axonal outgrowth, much better than they facilitated inhibitory fibroblast growth. Whilst the specific reasons for this are unclear, it is possible that at least part of the reason for this relates to tissue compliance mediated by a softer surface [70;71] presented on the formulations containing greater amounts of glycolic acid than lactic acid alone and as the respective formulations started to degrade with time. This possibility is highlighted by the progressively increased bioaffinity of the PC12 and RSC96 cells over a $72 \mathrm{hr}$ growth period compared to the lack of growth over this period observed by the Rat1-R12 cells.

It is important to note the competitive interrelationships between the three cell types at the site of nerve injury and the roles that each have in effective nerve regeneration: In the context of nerve repair in vivo, the neuronal attachment aspect does not require a proliferative component, but rather, involves axonal sprouting and extension over a prolonged period and is supported by Schwann cell activity. The strong bio-affinity dynamics showing a predominant RSC96 Schwann cell attachment at all stages over the first 72 hrs (Fig 1) are thus of relevance given that this potentially establishes early Schwann cell support for neuronal outgrowth on both polymers when implanted. Importantly, in this context, the affinity of the RSC96 cells for 85:15 PLGA is significantly greater than that of the Rat1-R12 fibroblasts throughout the $72 \mathrm{hr}$ period and is accompanied by likewise greater affinity of the neuronal PC12 cells for the polymer than that shown by the fibroblast cells at all stages. This establishes the rationale (presented by the schematics in Figs 1A to 1D) that the foundation biological activity on 85:15 fibers within the lumen of a nerve repair conduit at the site of transection would be axonal extension, supported by rapid "immediate" Schwann cell migration and proliferation. In this regard, the initial preference of the fibroblasts compared to the Schwann cells (Fig 1B) and the neuronal cells (Figs 1B and 1C) for the 75:25 PLGA formulation can be deemed negligible from a neuro-regenerative context given that the fibroblasts appear to enter a dormant (non-proliferative) state in latter stages (Figs 1C and 1D) in deference to Schwann and neuronal PC12 cells, which continue to populate the 75:25 surface. This rationale finds further support from the directional migration and growth of Schwann cells in conjunction with axonal extension of sensory neurons without excessive establishment of fibroblast populations from DRG explants on the fibers (Fig 2B). Likewise, these findings are consistent with others' reporting of similar neurite/Schwann cell growth dynamics on polypropylene fibers in vitro [47].

The Alginate/Fiber neuromatrix provided additional support over the individual pro-neural effects of the synthetic polymer components: The fibers in themselves were able to support guided Schwann cell migration and neuron outgrowth (Figs 2A compared with 2B), as evidenced by incursion of axons into the alginate when fibers were incorporated (Figs 2C to 2E), but not into the alginate hydrogel on its own (data not shown). Minimal in-growth achieved with neuromatrix in the absence of trophic factors (Fig 2C), was improved by addition of combinations of BDNF (Fig 2D) or NT-3 
(Fig 2E) with LIF, SMDF and MGF-1. Of all combinations evaluated, by far the best neuroregenerative effects were observed with full combinations utilizing BDNF/SMDF/LIF/MGF-1 (Fig 2D) or NT-3/SMDF/LIF/MGF-1 (Fig 2E) cocktails. Of these, the NT-3 variant conduit promoted the greatest growth response in DRG ex vivo. The inclusion of MGF-1 peptide in these configurations was observed to promote vast improvements in the extent of axonogenic incursion into the matrix along the fibers compared to biofactor cocktails from which the MGF-1 had been omitted. Again, others' observation that inclusion of biological factors (Laminin or Fibronectin) increased neurite outgrowth and Schwann cell migration within simulated nerve repair conduits using DRG explants in vitro, provides indirect support for the results presented here [47].

The final nerve repair conduit was thus assembled using the NT-3 version of the neuromatrix and implanted into axotomized rat sciatic nerve (Figs 3A to 3G) for a period of four weeks to repair a 12 mm gap. During this time, daily monitoring of general activity of the rats with the implanted conduits indicated some functional improvement albeit incomplete, in the implanted legs, as evidenced by progressive ambulatory improvement. This qualitative observation was supported by significantly reduced extent of autotomy in the axotomized legs of animals implanted with conduits containing the full neuromatrix compared to animals with conduits containing empty conduit sheaths (Fig 5C). These results concur with those of others that correlated autotomy with ineffective nerve repair due to anaesthesia of the paw on the nerve-transected limb [72] and suggest that the fully-configured conduit (ie sheath, NT-3/SMDF/LIF/MGF-1 neuromatrix hydrogel and fibers) restores some level of sensation in the axotomized limb (Fig 5B).

After the four-week implantation period, the sciatic nerves bridged by the nerve repair conduit were retrieved from the implanted rats, revealing patent nerve at regions proximal and distal to the conduit at the site of axotomy (Fig 4A). Immunological analysis of the bridged nerve segments indicated that the nerve upstream of the conduit was indeed patent, (Fig 4B), entered the nerve repair conduit (Fig 4C), and that axons grew through (Fig 4D) and beyond (Fig 4E) the conduit. This analysis also indicated that the PLGA guidance fibers within the neuromatrix were still hard, leaving "void" regions where the cryo-microtome encountered excessive resistance during sectioning. Similar results were reported by others with PLA fibers, which were clearly intact after a ten-week implantation period [61]. This aspect of the two materials' incorporation into nerve repair conduits represents a major challenge to their effectiveness, given the specific requirement of a relatively soft substrate for neurodifferentiation and neurite outgrowth demonstrated by others [70;73;74]. Immunohistological examination using $\beta$ III Tubulin ( $\beta$ III-T) and peripheral myelin protein (PMP) showed the presence of myelinated axons within the lumen of the conduit, and is consistent with others' having shown that a silicone cuff with PLA fibers of comparable dimensions to the conduit fabricated in this study support effective nerve regeneration in vivo [61].

Collectively, along with the above-mentioned and other similar studies within the literature, our results support the possibility that the full NT-3 configuration of our nerve repair conduit restored some sensation in the axotomized limbs through support of effective repair of the transected sciatic nerve. However, more detailed functional analyses (eg nerve conduction) are still required to fully quantify the extent of functional repair promoted by the conduit designed in this study.

This study has described the design and development via a relatively rapid in vitro process of a highly engineered multimodal, multicomponent nerve repair conduit and its application in vivo, to repair a $12 \mathrm{~mm}$ gap a rat sciatic nerve axotomy model of peripheral nerve trauma. Whilst the size of the gap repaired in this study largely reflects repairs achieved by others using the axotomized rat model [37;38;61;75;76], there have been some studies that have achieved repair of larger nerve gaps [61;77] using different materials and different configurations. However, these studies have universally demonstrated issues with their specific configurations that mitigate their potential for 
clinical application. Nevertheless, collectively there remains good rationale for further development of synthetic nerve conduits that will ultimately provide nerve repair as good or even superior to conventional nerve grafts [78-82]. It is clear that further work is required to improve their efficacy, particularly for the repair of longer nerve gaps [79;83] and the novel multimodal nerve repair concept applied in this study has shown an initial efficacy that may be further improved by inclusion of materials with better tissue compliance, fabricated into fiber formats with better physical and molecular facilitation of proper nerve repair. Likewise, further analysis of the extent of functionality gained through use of the nerve repair conduit described in this work will highlight the path towards improving this initial design towards clinical applicability.

\section{Acknowledgements:}

The authors would like to acknowledge funding provided by the Victorian Government Science, Technology and Innovation program, the National Health and Medical Research Council (Project 635243, the Australian Research Council (CE0561616) and the Commonwealth Scientific and Industrial Research Organization. The authors would also like to thank Mr Roberto and Ms Luana de Ioris for their support of this work. 


\section{Figure Legends:}

Figure 1. A schematic of the cut nerve/conduit interface is presented in panel (A) at $t=0 \mathrm{hr}$ after implant. The relevant nerve components represented on the schematic are axons (green lines), Schwann cells (red circles) and fibroblasts (blue circles), whilst conduit components shown are 85:15 and 75:25 PLGA (grey and black lines respectively) and alginate hydrogel (white spaces in the conduit section). The projected/expected in vivo growth behaviour of the three nerve components, based on relative in vitro affinities of representative nerve cell types to the 75:25 and 85:15 PLGA formulations over a $72 \mathrm{hr}$ period is outlined schematically below the graphs through $1 \mathrm{~B}$ to $1 \mathrm{D}$. The graphs depict the affinity of the 75:25 and 85:15 polymers to PC12 neuronal, RSC96 Schwann and 1R12 fibroblast cells at the early "immediate" attachment (6 hrs) stage (B), an early proliferative "initial” attachment (24 hrs) stage (C), and a later proliferative "sustained" attachment (72 hrs) stage (D). The strong affinity of the 75:25 and 85:15 polymers to the RSC96 Schwann cells potentially establishes a trophic basis for axonal outgrowth via early Schwann cell attachment predominantly on the 85:15 fibers and to a lesser degree on the 75:15 fibers, but with some competition from the fibroblasts on the latter (fiorst 6 hrs, B). The pro-neurogenic environment established at the immediate stages of nerve re-growth within the conduit lumen would thus be maintained over the first 24 hrs, with a slight consolidation of this effect via increased affinity of the Schwann cells for the 75:25 polymer and increased affinity for neuronal attachment on the 85:15 polymer compared to fibroblasts (C). Over the next 48 hrs, the original attachment profile is further consolidated and augmented by a significant drop in the relative proliferative affinity of fibroblasts on both polymers (which do not proliferate over this time). This combines with increased neuronal attachment on the 75:25 and 85:15 polymer formulations with undiminished (strong) affinity of the Schwann cells for both formulations. The added trophic environment of the hydrogel for the support of Schwann cell and neurotrophic/neuroprotective activities provides further bias towards a preferential neuroregenerative outcome selectively promoting Schwann cells and axonal outgrowth in preference to a cell-mediated fibrotic outcome.

Figure 2. Dorsal Root Ganglia (DRG) were grown on flat laminin-coated substrate (A) and the same substrate with PLGA (75:25 and 85:15) microfibers [45;46] (B) to evaluate the effect of microstructure on the growth of the DRG. The microfibers were seen to promote guided linear growth of axons (green, $\beta$ III Tubulin) with Schwann cells (red, S100 $\beta$ ) juxtapose to the growing axons. Regions of fibroblast growth were defined by DAPI staining in absence of $\mathrm{S} 100 \beta(\mathrm{Fb})$ and in accordance with previous observations using cell lines (Fig 1), showed that support of fibrogenic growth was likely to be minimal compared to neural and neuroglial growth if these materials were to be incorporated into a nerve repair conduit. The DRG were also grown for one month in polyethylene tubing containing PLGA laminin coated fibers and $0.75 \%$ alginate ( $C$ to $H$ ) to simulate the neuromatrix lumen of the proposed nerve repair conduit. The panels show fluorescent labelling of Schwann cell nuclei which is visible in the panels as very bright white dots. This highlights the extent to which the Schwann cells migrate/grow from the DRG during the month period for which they were grown. Required concentrations of each respective bio-factor were optimized in separate in vitro experiments prior to finalization of the bio-factor cocktail within the neuromatrix alginate hydrogel (data not shown). Neuromatrix versions shown are with no growth factor (C), $50 \mathrm{ng} / \mathrm{ml}$ of BDNF, SMDF, LIF, and MGF (D), $50 \mathrm{ng} / \mathrm{ml}$ NT3, SMDF, LIF, and MGF (E),. Cells were fixed with $4 \%$ paraformaldehyde and permeabilized with $0.02 \%$ Triton-X100. Pictures show DAPI staining of cell nuclei and the hydrogel shown to most optimally promote neurogenic activity contained 50 $\mathrm{ng} / \mathrm{ml}$ NT3, SMDF, LIF, and MGF (E), as evident by the greatets degree of Schwann cell migration from the DRG.

Figure 3. The process of the nerve repair conduit engineering consisted of fiber extrusion (A), knitting of the conduit infrastructure using PLA (B), electrospinning a PLA membrane on the outside 
of the knitted sheath (C) with controlled pore size of approximately $2 \mu \mathrm{m}$ (D). The full conduit contained fiber components selective for nerve growth guidance and Schwann cell growth over the proliferation of fibroblasts (E), with the internal guidance fibers provided separately to the conduit to allow the assembly with a fresh multimodal hydrogel containing growth factors (final configuration with MGF-1, LIF, NT-3 and SMDF) (F) immediately prior to surgical implantation (conduit indicated by the black arrow) into rats with axotomized sciatic nerves $(G)$.

Figure 4. The conduits were implanted in the rats for a period of four weeks after which they were removed. Initial examination revealed patent nerve both proximal and distal to the repaired axotomy site (A) and immunohistological assessment ( $\beta$ III Tubulin, axons; Red; DAPI Schwann cell nuclei) indicated the presence of axonal tissue in the treated nerve before (B), at the entry (C) within the midsection (D) and outside distal (E) to the conduit. There were void regions (Void; V) that resulted from the residual hardness of the polymers used to make the fibers and were generated during microsectioning. Address of this aspect with more tissue-compliant polymers stands to greatly improve the effectiveness of future versions of the nerve repair conduit. The dotted line represents border edges of the conduit.

Figure 5. Myelinated axons were observed within the lumen of the nerve repair conduits implanted in the axotomized rats. Using $\beta$ III Tubulin (red) and peripheral myelin protein (PMP; green) myelinated axons can be observed within the nerve tissue (A). Myelinated axons were observed within the proximal mid-sectional (B) and distal regions of the Nerve repair conduits implanted in the rats. (C). The level of autotomy of rats' limbs implanted with either empty (sham; $n=4$ ) or fully assembled conduits $(n=4)$ revealed that the rats with fully assembled implants performed less autotomy than did rats with "empty (sham)" conduits that did not contain fibers or neuromatrix. This indicated that the fully assembled conduits restored sufficient sensation of pain to prevent excessive autotomy in the implanted recipient subjects. Abbreviation (B):- NeRPS=Nerve Repair Polymer Scaffold. 


\section{References}

[1] Taylor CA, Braza D, Rice JB, Dillingham T. The incidence of peripheral nerve injury in extremity trauma. Am J Phys Med Rehabil 2008 May;87(5):381-5.

[2] Evans GR. Peripheral nerve injury: a review and approach to tissue engineered constructs. Anat Rec 2001 Aug 1;263(4):396-404.

[3] Bagai K, Wilson JR, Khanna M, Song Y, Wang L, Fisher MA. Electrophysiological patterns of diabetic polyneuropathy. Electromyogr Clin Neurophysiol 2008 Apr;48(3-4):139-45.

[4] Zochodne DW, Guo GF, Magnowski B, Bangash M. Regenerative failure of diabetic nerves bridging transection injuries. Diabetes Metab Res Rev 2007 Sep;23(6):490-6.

[5] Sunderland SS. Nerves and Nerve Injuries. 2 ed. Edinburgh: Churchill Livingstone; 1978.

[6] Brushart TM. Nerve Repair and Grafting. Green's Operative Hand Surgery. 4 ed. Philadelphia: Churchill livingstone; 1999. p. 1381-403.

[7] Trumble TE, McCallister WV. Repair of peripheral nerve defects in the upper extremity. Hand Clin 2000 Feb;16(1):37-52.

[8] Diao E, Vannuyen T. Techniques for primary nerve repair. Hand Clin 2000 Feb;16(1):53-66, viii.

[9] Lundborg G. Nerve Injury and Repair:Regeneration, Reconstruction, and Cortical Remodelling. 2 ed. Philadelphia: Churchill Livingstone; 2005.

[10] Kalbermatten DF, Pettersson J, Kingham PJ, Pierer G, Wiberg M, Terenghi G. New fibrin conduit for peripheral nerve repair. J Reconstr Microsurg 2009 Jan;25(1):27-33.

[11] Bian YZ, Wang Y, Aibaidoula G, Chen GQ, Wu Q. Evaluation of poly(3-hydroxybutyrateco-3-hydroxyhexanoate) conduits for peripheral nerve regeneration. Biomaterials 2009 Jan;30(2):217-25.

[12] Hsu SH, Su CH, Chiu IM. A novel approach to align adult neural stem cells on micropatterned conduits for peripheral nerve regeneration: a feasibility study. Artif Organs 2009 Jan;33(1):26-35.

[13] Yao L, O'Brien N, Windebank A, Pandit A. Orienting neurite growth in electrospun fibrous neural conduits. J Biomed Mater Res B Appl Biomater 2009 Jan 7;90:483-91.

[14] Kalbermatten DF, Kingham PJ, Mahay D, Mantovani C, Pettersson J, Raffoul W, et al. Fibrin matrix for suspension of regenerative cells in an artificial nerve conduit. J Plast Reconstr Aesthet Surg 2008 Jun;61(6):669-75.

[15] Lu M C, Huang Y T, Lin J H, Yao C H, Lou C W, Tsai C C and Chen Y S. Evaluation of a multi-layer microbraided polylactic acid fiber-reinforced conduit for peripheral nerve regeneration. J Mater Sci Mater Med 2008 Dec 30;20:1175-80. 
[16] Giardino R, Nicoli Aldini N, Perego G, Cella G, Maltarello M C, Fini M, Rocca M and Giavaresi G. Biological and synthetic conduits in peripheral nerve repair: a comparative experimental study. Int J Artif Organs 1995 Apr;18(4):225-30.

[17] Lundborg G. Neurotropism, frozen muscle grafts and other conduits. J Hand Surg [Br ] 1991 Dec;16(5):473-6.

[18] Mackinnon SE, Dellon AL. A study of nerve regeneration across synthetic (Maxon) and biologic (collagen) nerve conduits for nerve gaps up to $5 \mathrm{~cm}$ in the primate. $\mathrm{J}$ Reconstr Microsurg 1990 Apr;6(2):117-21.

[19] Francel P C, Smith K S, Stevens F A, Kim S C, Gossett C, Davis M E, Lenaerts M and Tompkins P. Regeneration of rat sciatic nerve across a LactoSorb bioresorbable conduit with interposed short-segment nerve grafts. J Neurosurg 2003 Sep;99(3):549-54.

[20] Evans GR, Brandt K, Widmer MS, Lu L, Meszlenyi RK, Gupta PK, et al. In vivo evaluation of poly(L-lactic acid) porous conduits for peripheral nerve regeneration. Biomaterials 1999 Jun;20(12):1109-15.

[21] Lloyd B M, Luginbuhl R D, Brenner M J, Rocque B G, Tung T H, Myckatyn T M, Hunter D A, Mackinnon S E and Borschel G H. Use of motor nerve material in peripheral nerve repair with conduits. Microsurgery 2007;27(2):138-45.

[22] Keskin M, Akbas H, Uysal O A, Canan S, Ayyldz M, Agar E and Kaplan S. Enhancement of nerve regeneration and orientation across a gap with a nerve graft within a vein conduit graft: a functional, stereological, and electrophysiological study. Plast Reconstr Surg 2004 Apr 15;113(5):1372-9.

[23] Mohammad JA, Warnke PH, Pan YC, Shenaq S. Increased axonal regeneration through a biodegradable amnionic tube nerve conduit: effect of local delivery and incorporation of nerve growth factor/hyaluronic acid media. Ann Plast Surg 2000 Jan;44(1):59-64.

[24] Kim YT, Haftel VK, Kumar S, Bellamkonda RV. The role of aligned polymer fiber-based constructs in the bridging of long peripheral nerve gaps. Biomaterials 2008 Jul;29(21):311727.

[25] Toba T, Nakamura T, Lynn A K, Matsumoto K, Fukuda S, Yoshitani M, Hori Y and Shimizu Y. Evaluation of peripheral nerve regeneration across an 80 -mm gap using a polyglycolic acid (PGA)-collagen nerve conduit filled with laminin-soaked collagen sponge in dogs. Int J Artif Organs 2002 Mar;25(3):230-7.

[26] Pfister LA, Papaloizos M, Merkle HP, Gander B. Hydrogel nerve conduits produced from alginate/chitosan complexes. J Biomed Mater Res A 2007 Mar 15;80(4):932-7.

[27] Weber RA, Breidenbach WC, Brown RE, Jabaley ME, Mass DP. A randomized prospective study of polyglycolic acid conduits for digital nerve reconstruction in humans. Plast Reconstr Surg 2000 Oct;106(5):1036-45.

[28] Lohmeyer JA, Siemers F, Machens HG, Mailander P. The clinical use of artificial nerve conduits for digital nerve repair: a prospective cohort study and literature review. J Reconstr Microsurg 2009 Jan;25(1):55-61. 
[29] Azhar MM, Sara TA. Comparison of nerve graft and artificial conduits for bridging nerve defects. Med J Malaysia 2004 Dec;59(5):578-84.

[30] Kim J, Dellon AL. Reconstruction of a painful post-traumatic medial plantar neuroma with a bioabsorbable nerve conduit: a case report. J Foot Ankle Surg 2001 Sep;40(5):318-23.

[31] Ward JD. Improving prognosis in type 2 diabetes. Diabetic neuropathy is in trouble. Diabetes Care 1999 Mar;22 Suppl 2:B84-B88.

[32] Hudson TW, Evans GR, Schmidt CE. Engineering strategies for peripheral nerve repair. Orthop Clin North Am 2000 Jul;31(3):485-98.

[33] Yang Y, De Laporte L, Rives CB, Jang JH, Lin WC, Shull KR, et al. Neurotrophin releasing single and multiple lumen nerve conduits. J Control Release 2005 Jun 2;104(3):433-46.

[34] Sterne GD, Brown RA, Green CJ, Terenghi G. Neurotrophin-3 delivered locally via fibronectin mats enhances peripheral nerve regeneration. Eur J Neurosci 1997 Jul;9(7):138896.

[35] Hontanilla B, Auba C, Gorria O. Nerve regeneration through nerve autografts after local administration of brain-derived neurotrophic factor with osmotic pumps. Neurosurgery 2007 Dec;61(6):1268-74.

[36] Dowsing BJ, Hayes A, Bennett TM, Morrison WA, Messina A. Effects of LIF dose and laminin plus fibronectin on axotomized sciatic nerves. Muscle Nerve 2000 Sep;23(9):135664.

[37] Bennett TM, Dowsing BJ, Austin L, Messina A, Nicola NA, Morrison WA. Anterograde transport of leukemia inhibitory factor within transected sciatic nerves. Muscle Nerve 1999 Jan;22(1):78-87.

[38] Tham S, Dowsing B, Finkelstein D, Donato R, Cheema SS, Bartlett PF, et al. Leukemia inhibitory factor enhances the regeneration of transected rat sciatic nerve and the function of reinnervated muscle. J Neurosci Res 1997 Jan 15;47(2):208-15.

[39] Austin L, Bower JJ, Kurek JB, Muldoon CM. Controlled release of leukaemia inhibitory factor (LIF) to tissues. Growth Factors 1997;15(1):61-8.

[40] Mohanna PN, Terenghi G, Wiberg M. Composite PHB-GGF conduit for long nerve gap repair: a long-term evaluation. Scand J Plast Reconstr Surg Hand Surg 2005;39(3):129-37.

[41] Cui T, Yan Y, Zhang R, Liu L, Xu W, Wang X. Rapid prototyping of a double-layer polyurethane-collagen conduit for peripheral nerve regeneration. Tissue Eng Part C Methods 2009 Mar;15(1):1-9.

[42] Whitlock EL, Tuffaha SH, Luciano JP, Yan Y, Hunter DA, Magill CK, et al. Processed allografts and type I collagen conduits for repair of peripheral nerve gaps. Muscle Nerve 2009 Jun;39(6):787-99.

[43] Siemionow M, Brzezicki G. Chapter 8: Current techniques and concepts in peripheral nerve repair. Int Rev Neurobiol 2009;87:141-72. 
[44] Bryan DJ, Holway AH, Wang KK, Silva AE, Trantolo DJ, Wise D, et al. Influence of glial growth factor and Schwann cells in a bioresorbable guidance channel on peripheral nerve regeneration. Tissue Eng 2000 Apr;6(2):129-38.

[45] Quigley A.F., Razal J.M., Thompson B.C., Moulton S.E., Kita M., Kennedy EL, Clark GM, Wallace GG and Kapsa RMI. A Conducting Polymer Platform with Biodegradable Fibers for Stimulation and Guidance of Axonal Growth. Adv Mater 2009;21(43):4393-7.

[46] Razal JM, Kita M, Quigley AF, Kennedy E, Moulton SE, Kapsa RMI, Clark GM and Wallace GG. Wet-Spun Biodegradable Fibers on Conducting Platforms: Novel Architectures for Muscle Regeneration. Adv Funct Mater 2009;19:3381-88.

[47] Wen X, Tresco PA. Effect of filament diameter and extracellular matrix molecule precoating on neurite outgrowth and Schwann cell behavior on multifilament entubulation bridging device in vitro. J Biomed Mater Res 2006;76A(3):626-37.

[48] Vleggeert-Lankamp CL, de Ruiter GC, Wolfs JF, Pego AP, van den Berg RJ, Feirabend HK, et al. Pores in synthetic nerve conduits are beneficial to regeneration. J Biomed Mater Res A 2007 Mar 15;80(4):965-82.

[49] Gorecki DC, Beresewicz M, Zablocka B. Neuroprotective effects of short peptides derived from the Insulin-like growth factor 1. Neurochem Int 2007 Dec;51(8):451-8.

[50] Chung H, Seo S, Moon M, Park S. IGF-I inhibition of apoptosis is associated with decreased expression of prostate apoptosis response-4. J Endocrinol 2007 Jul;194(1):77-85.

[51] Dluzniewska J, Sarnowska A, Beresewicz M, Johnson I, Srai SK, Ramesh B, et al. A strong neuroprotective effect of the autonomous C-terminal peptide of IGF-1 Ec (MGF) in brain ischemia. FASEB J 2005 Nov;19(13):1896-8.

[52] Osheroff PL, Tsai SP, Chiang NY, King KL, Li R, Lewis GD, et al. Receptor binding and biological activity of mammalian expressed sensory and motor neuron-derived factor (SMDF). Growth Factors 1999;16(3):241-53.

[53] Schroering A, Carey DJ. Sensory and motor neuron-derived factor is a transmembrane heregulin that is expressed on the plasma membrane with the active domain exposed to the extracellular environment. J Biol Chem 1998 Nov 13;273(46):30643-50.

[54] Huang EJ, Reichardt LF. Neurotrophins: roles in neuronal development and function. Annu Rev Neurosci 2001;24:677-736.

[55] Sakamoto T, Kawazoe Y, Shen JS, Takeda Y, Arakawa Y, Ogawa J, et al. Adenoviral gene transfer of GDNF, BDNF and TGF beta 2, but not CNTF, cardiotrophin-1 or IGF1, protects injured adult motoneurons after facial nerve avulsion. J Neurosci Res 2003 Apr 1;72(1):5464.

[56] Hohlfeld R, Kerschensteiner M, Stadelmann C, Lassmann H, Wekerle H. The neuroprotective effect of inflammation: implications for the therapy of multiple sclerosis. 2006 Mar 18; Neurol Sci 27:S1-S7.

[57] Ho WH, Armanini MP, Nuijens A, Phillips HS, Osheroff PL. Sensory and Motor Neuronderived Factor. A NOVEL HEREGULIN VARIANT HIGHLY EXPRESSED IN SENSORY 
AND MOTOR NEURONS. Journal of Biological Chemistry 1995 Jun 16;270(24 4):1452332.

[58] Riddoch-Contreras J, Yang SY, Dick JR, Goldspink G, Orrell RW, Greensmith L. Mechanogrowth factor, an IGF-I splice variant, rescues motoneurons and improves muscle function in SOD1(G93A) mice. Exp Neurol 2009 Feb;215(2):281-9.

[59] Matheny RW, Jr., Nindl BC, Adamo ML. Minireview: Mechano-growth factor: a putative product of IGF-I gene expression involved in tissue repair and regeneration. Endocrinology 2010 Mar;151(3):865-75.

[60] Meijering E, Jacob M, Sarria JC, Steiner P, Hirling H, Unser M. Design and validation of a tool for neurite tracing and analysis in fluorescence microscopy images. Cytometry A 2004 Apr;58(2):167-76.

[61] Ngo TTB, Waggoner PJ, Romero AA, Nelson KD, Eberhart RC, Smith GM. Poly(L-Lactide) microfilaments enhance peripheral nerve regeneration across extended nerve lesions. Journal of Neuroscience Research 2003;72(2):227-38.

[62] Wall PD, Devor M, Inbal R, Scadding JW, Schonfeld D, Seltzer Z, et al. Autotomy following peripheral nerve lesions: experimental anaesthesia dolorosa. Pain 1979 Oct;7(2):103-11.

[63] Kauppila T. Nerve resuturation decreases autotomy in the rat. Exp Neurol 1994 Jan;125(1):106-10.

[64] Okuda T, Ishida O, Fujimoto Y, Tanaka N, Inoue A, Nakata Y, et al. The autotomy relief effect of a silicone tube covering the proximal nerve stump. J Orthop Res 2006 Jul;24(7):1427-37.

[65] Richardson RT, Wise AK, Thompson BC, Flynn BO, Atkinson PJ, Fretwell NJ, et al. Polypyrrole-coated electrodes for the delivery of charge and neurotrophins to cochlear neurons. Biomaterials 2009 May;30(13):2614-24.

[66] Evans AJ, Thompson BC, Wallace GG, Millard R, O'Leary SJ, Clark GM, et al. Promoting neurite outgrowth from spiral ganglion neuron explants using polypyrrole/BDNF-coated electrodes. J Biomed Mater Res A 2008 Sep 23;91A:241-250.

[67] Richardson RT, Thompson B, Moulton S, Newbold C, Lum MG, Cameron A, et al. The effect of polypyrrole with incorporated neurotrophin-3 on the promotion of neurite outgrowth from auditory neurons. Biomaterials 2007 Jan;28(3):513-23.

[68] Yamauchi J, Chan JR, Shooter EM. Neurotrophins regulate Schwann cell migration by activating divergent signaling pathways dependent on Rho GTPases. Proc Natl Acad Sci U S A 2004 Jun 8;101(23):8774-9.

[69] Aperghis M, Johnson IP, Cannon J, Yang SY, Goldspink G. Different levels of neuroprotection by two insulin-like growth factor-I splice variants. Brain Res 2004 May 29;1009(1-2):213-8.

[70] Sundararaghavan HG, Monteiro GA, Firestein BL, Shreiber DI. Neurite growth in 3D collagen gels with gradients of mechanical properties. Biotechnol Bioeng 2009 Feb 1;102(2):632-43. 
[71] Jiang FX, Yurke B, Firestein BL, Langrana NA. Neurite outgrowth on a DNA crosslinked hydrogel with tunable stiffnesses. Ann Biomed Eng 2008 Sep;36(9):1565-79.

[72] Meek MF, Dijkstra JR, Den Dunnen WF, Ijkema-Paassen J, Schakenraad JM, Gramsbergen A, et al. Functional assessment of sciatic nerve reconstruction: biodegradable poly (DLLAepsilon-CL) nerve guides versus autologous nerve grafts. Microsurgery 1999;19(8):381-8.

[73] Gunn JW, Turner SD, Mann BK. Adhesive and mechanical properties of hydrogels influence neurite extension. J Biomed Mater Res A 2005 Jan 1;72(1):91-7.

[74] Miller C, Jeftinija S, Mallapragada S. Synergistic effects of physical and chemical guidance cues on neurite alignment and outgrowth on biodegradable polymer substrates. Tissue Eng 2002 Jul;8(3):367-78.

[75] Kim SM, Lee SK, Lee JH. Peripheral nerve regeneration using a three dimensionally cultured schwann cell conduit. J Craniofac Surg 2007 May;18(3):475-88.

[76] Waitayawinyu T, Parisi DM, Miller B, Luria S, Morton HJ, Chin SH, et al. A comparison of polyglycolic acid versus type 1 collagen bioabsorbable nerve conduits in a rat model: an alternative to autografting. J Hand Surg [Am ] 2007 Dec;32(10):1521-9.

[77] Wei AL, Liu SQ, Tao HY, Peng H. Repairing peripheral nerve defects with tissue engineered artificial nerves in rats. Chin J Traumatol 2008 Feb;11(1):28-33.

[78] Ichihara S, Inada Y, Nakada A, Endo K, Azuma T, Nakai R, et al. Development of New Nerve Guide Tube for Repair of Long Nerve Defects. Tissue Eng Part C Methods 2009 Feb 17;15:387-402.

[79] Tomita K, Kubo T, Matsuda K, Hattori R, Fujiwara T, Yano K, et al. Effect of conduit repair on aberrant motor axon growth within the nerve graft in rats. Microsurgery 2007;27(5):500-9.

[80] Reyes O, Sosa IJ, Santiago J, Kuffler DP. A novel technique leading to complete sensory and motor recovery across a long peripheral nerve gap. P R Health Sci J 2007 Sep;26(3):225-8.

[81] Meek MF, Coert JH, Robinson PH. Poor results after nerve grafting in the upper extremity: Quo vadis? Microsurgery 2005;25(5):396-402.

[82] Wang X, Hu W, Cao Y, Yao J, Wu J, Gu X. Dog sciatic nerve regeneration across a 30-mm defect bridged by a chitosan/PGA artificial nerve graft. Brain 2005 Aug;128(Pt 8):1897-910.

[83] Moore AM, Kasukurthi R, Magill CK, Farhadi HF, Borschel GH, Mackinnon SE. Limitations of Conduits in Peripheral Nerve Repairs. Hand (N Y ) 2009 Jan 10;4:180-186. 